\title{
The efficacy of circle of security on attachment and well-being in preschool children
}

\author{
Akram Dehghani $^{\mathrm{a}^{*}}$, Mokhtar Malekpour ${ }^{\mathrm{b}}$, Ahmad Abedi ${ }^{\mathrm{c}}$ and Shole Amiri ${ }^{\mathrm{b}}$
}

${ }^{a} \mathrm{PhD}$. Student in psychology, Department of psychology, University of Isfahan, Hezar Jarib Isfahan , Iran

${ }^{b} \mathrm{PhD}$. In Psychology, Assistant prof. of Isfahan University, Psychology Department, Iran

${ }^{c}$ PhD. in Psychology, Psychology Department of Children with Special Needs, Assistant Professor of Isfahan University, Iran

\section{H R O N I C L E \\ A B S T R A C T}

Article history:

Received June 28, 2013

Received in revised format

19 October 2013

Accepted 20 December 2013

Available online

December 272013

\section{Keywords:}

Circle of Security

Attachment

Well-being

Preschool children

\begin{abstract}
The purpose of this study was to determine the efficacy of Circle of Security (COS) on preschool children's attachment and well-being. 48 mothers with children's age 4 to 6 year were randomly selected through cluster sampling and randomly assigned to experimental and control groups (24 mothers and child in each group). Then the experimental group received 20 weekly COS sessions in the center of preschool. The attachment Q-set and Preschool children wellbeing questionnaire (PCWQ) were used as the pretest, post-test and in the course of follow-up. Results of Multivariate Analysis of Covariance (MANCOVA) showed that the mean scores of attachment, in the experimental group, was significantly greater than the control group in posttest $(\mathrm{P}=0.000)$ and follow-up $(\mathrm{P}=0.002)$. Results also showed that the scores of well-being in experimental group was significantly greater than the control group in post-test $(\mathrm{P}=0.006)$ and follow-up $(\mathrm{P}=0.018)$. The finding of the study emphasized the importance of training of attachment in improvement of preschool children's attachment and well-being. More studies are suggested to understand better efficacy of maternal behavior on preschool children's well-being.
\end{abstract}

C 2014 Growing Science Ltd. All rights reserved.

\section{Introduction}

Interest in child well-being and reports and studies on this issue has significantly increased since 1990s. The initial studies on child well-being tended to concentrate on child survival (Lippman, 2007; Ben-Arieh, 2008) but, over the past 15 years, a theoretical shift has happened to understand the development of children (Lerner \& Benson, 2004; Scales \& Benson, 2005). Perhaps most important issue for discussion of positive child development is the concept of viewing children as a specific group, which differs from other age groups (e.g., adults, the elderly) and has value in its own right, rather than value only as future adults. From a child rights perspective well-being can be defined as the realization of children's rights and the fulfillment of the opportunity for every child to be all he or she can be (Bradshaw et al., 2007). Theories of child development are inherently positive towards the

*Corresponding author. Tel: +98-9131263604

E-mail addresses: ddehghani55@yahoo.com (A. Dehghani) 
extent that they describe how a healthy child develops over time in a supportive environment. Developmental stage theories such as Erikson's (1968) psychosocial theory and ecological approaches such as Bronfenbrenner's (1986) theory provide a concept that explains child positive development. The developmental theories demonstrate that children and their environments interact continually in the developmental process. Child-context interactions influence growth not only in obvious domains such as physical development, but also in psychological, social, and cognitive areas as well. The importance of contextual factors on children well-being is emphasized in the realm of children's rights. Convention on the Rights of the Child (CRC) spells out broad international agreement about children's rights to well-being in a comprehensive array of contextual domains extending from family to school, cultural centers, religious organizations, recreation areas, and other parts of the community (Lippman et al., 2011).

Extensive literature on the development of child well-being focuses on the role of child-parent relationships quality and secures attachments. Bowlby $(2005,2008)$ defines attachment as an enduring emotional bond that child forms to another person. He focused that attachment is referred to the young child's strong disposition to seek proximity to and to contact with a specific figure and to do so in certain situations, notably when frightened, tired, or ill (Rutter, 2008). Although all children become attached to their caregivers, there are variations in the security of attachments. When parents provide sensitive and responsive care, their children are more security attached. By definition, a child who is securely attached is able to use the parent as both a source of comfort (safe haven) and as a secure base to explore the environment. A child also develops positive mental representations, or internal working models (IWMs; i.e., Ainsworth et al., 1978; Weinfield et al., 2008), which captures expectations and beliefs about the self (e.g., whether the child is worthy of attention and care) and others (e.g., whether others are likely to be responsive and available) ( West et al., 2012). These representations as persistent and yet open to revision in light of experience. Persistent attachment representations allow positive secure base experiences to guide behavior when someone "stronger and wiser" is not at hand (Bowlby, 1985). The early relationship between caregiver and child acts as an external system for the child's internal regulation (Malekpour, 2007).

In relationship-based child welfare services, interventions would focus on the repair or support of relationships between a maltreated child and parents, based on an attachment framework. In a review of attachment-based intervention programs, Berlin et al. (2008) outlined three "therapeutic tasks" for attachment-based interventions: (1) parent's internal working models, (2) parent's behaviors toward the child, and (3) parent's relationship with an intervener. The first and the second task focus on parents, based on the assumption that enhancement of a parent's relationship capacity will lead to changes in a child's internal working models and behaviors. The third task serves as the "engine" for interventions and change processes. The Circle of Security (COS) of relationship enhancing interventions is based on this framework.

The COS intervention protocol is a 20 -week, group-based, parent education and psychotherapy intervention designed to shift patterns of attachment in caregiver-child dyads to a more appropriate developmental pathway. The intervention involves small $(\mathrm{N}=6)$ groups of toddlers or pre-scholars, who meet as a group with a psychotherapist an hour and a quarter each week. All phases of the COS are based on attachment theory and procedures, current research on early relationships, and object relations theory (Marvin et al., 2002). Especially important among these are the ideas of emotion regulation, interactive synchrony, and states of mind regarding attachments and intimate relationships, affect, states of consciousness, perspectives, and reflective functioning. The core constructs of the protocol are Ainsworth's ideas of a Secure Base and a Haven of Safety (Ainsworth et al., 1978). A basic component of this protocol is that smooth interactions between children and their caregivers are often disrupted and need repair (Bowlby, 2005, 2008; Tronick, 1989). However, the caregiver as an adult has more 'degrees of freedom' in changing patterns of attachment-caregiving interactions than does the child. Rather, the implication is that even for a preschooler, a most 
effective intervention for problematic attachment-caregiving patterns may be to focus directly on the caregiver, and work toward shifting the caregiver's patterns of behavior and her IWMs of attachmentcaregiving interactions with this particular child. This shift should then lead to a change in patterns of parent-child interaction and in turn shift the child's patterns of attachment- and exploratory-behavior toward a more adaptive developmental pathway. In the context of a supportive group environment in which the therapist has taken on the role of a secure based for the participants, each caregiver is guided at her own pace toward increased skill in reading the child's cues, reflecting on the child's thoughts and feelings, and reflecting on her own feelings, plans and behavior.

The COS diagram shows a circle held between two hands. One hand supports the top half of the circle, showing the secure base of support children need for play and learning. The hand supporting the bottom half of the circle represents the safe haven children need when they have had enough of exploring.

The Preschool children well-being assesses well-being in dimensions of emotional, social, educational, cognition, family, etc. Many studies demonstrated significant and positive associations between attachment style and subscales of well-being; for instance: dimension of emotional (Brown \& Whiteside, 2008; Panfil et al., 2012; Baker \& Hoerger, 2012), social (Baker \& Hoerger, 2012), and cognition (West et al., 2012). However, the authors did not find studies about the relationship between attachment and well-being. Thus, in this study, following hypotheses were tested:

Training of COS to mothers will be associated with increasing of preschool children attachment. Training of COS to mothers will be associated with increasing of preschool children well-being.

\section{Methods}

The design of this study was experimental trail, using two groups of experimental and control. A preintervention-post-intervention-follow up design was used to examine intervention effectiveness, with child attachment and well-being as the outcome measure. The study population included all centers of preschool in Isfahan city. One center was randomly selected through multiple stage clusters. Sample was consisted of 48 preschool children and each child's primary caregiver who were randomly selected and assigned to experiment (24 cases) and control (24 cases) groups. The experimental group included two six-member subgroups. Mothers were chosen to participate because of the likelihood that they were the children's primary caregivers. The primary criteria were parent availability to participate in the group and a history of regularity in bringing the child to the center.

With few exceptions, invited families agreed to participate. Participation was voluntary and mothers were entered into a drawing for a cash prize that took place at the completion of the research. Children received an animal doll in the last session. Experimental group received 20 weekly COS sessions (see Marvin et al., 2002) in the center of preschool. Assessment of intervention effectiveness was based on measuring child attachment with Q-set and wellbeing child with PCWQ at 2 weeks prior to intervention and again approximately 10 days following the completion of the 20 - week intervention. The follow-up tests were conducted three months after the last intervention session. Qset and PCWQ were completed by the mothers. All questionnaires (24 Q-set consist of 12 preinterventions and 12 post interventions, and 24 PCWQ consist of 12 pre-interventions and 12 post interventions) were assessed after post intervention. After the sessions of experimental group, five training sessions of attachment style was set for control group.

\section{Measures}

Attachment Q-set: Children's attachment security at pre and posttest was assessed with the Attachment Q-set (see Waters \& Deane, 1985). The mothers completed the Attachment Q-set, which 
consists of 90 cards, each depicting behavioral characteristics of children. The mother sorted the items into nine piles, from "most characteristic of the child" to "least characteristic of the child". The placement of the cards in the sort determines the child's score for an item, with the resulting profile then correlated with the profile of a secure child to derive a security score. The inter-rater reliability for the Attachment Q-set was 0.73 (McCartney et al., 2004; West et al., 2012). This questionnaire in Iran translated by Tabae Emami (2011), and its reliability examined.

Preschool children well-being questionnaire (PCWQ): This questionnaire was designed by Dehghani et al. (2013) in Iran. This questionnaire assesses Preschool children well-being and consists of 41 items. Items are answered using a five-point Likert scale (1: never 2: seldom 3: moderate 4: often 5: most of the time) with a total score ranging between 0 and 5 . Higher scores reflect greater levels of well-being. Dimensions of PCWQ include Emotional, Social, Educational, Cognition, and family. Cronbach alphas for these items were calculated as $0.73,0.83,0.77,0.70,0.73$, respectively and total Cronbach alpha was equal to 0.89 . The current study utilized the total score, rather than score of dimensions.

\section{Results}

Characteristics of demographic of the sample are presented in Table 1 where 7 (58\%) were girl and 66\% were 5-6 years. Mothers aged from 25 to 44, and 75\% had at least a college degree or higher. The mean and standard deviation of the pre-test, post-test and follow up test of preschool child mothers in the two groups are presented in Table 2.

\section{Table 1}

Demographic characteristics of sample

\begin{tabular}{|c|c|c|c|c|c|c|}
\hline & \multirow[b]{2}{*}{ Index variable } & & \multicolumn{2}{|c|}{ Experimental } & \multicolumn{2}{|c|}{ Control } \\
\hline & & & Frequency & Percent & Frequency & Percent \\
\hline \multirow[t]{4}{*}{ Mothers } & Educational level & $<=12$ years & 3 & 25 & 4 & 34 \\
\hline & & $>12$ & 9 & 75 & 8 & 66 \\
\hline & Age & $20-30$ & 5 & 42 & 6 & 50 \\
\hline & & $31-45$ & 7 & 58 & 6 & 50 \\
\hline \multirow[t]{4}{*}{ Children } & Gender & Girl & 7 & 58 & 6 & 50 \\
\hline & & Boy & 5 & 42 & 6 & 50 \\
\hline & Age & $4-5$ & 4 & 34 & 5 & 42 \\
\hline & & $5-6$ & 8 & 66 & 7 & 58 \\
\hline
\end{tabular}

Table 2

The mean and standard deviation in attachment and well-being

\begin{tabular}{lllllll}
\hline Stage & $\begin{array}{l}\text { Pre-experiment } \\
\text { Control }\end{array}$ & Experiment & $\begin{array}{l}\text { Post-experiment } \\
\text { Control }\end{array}$ & Experiment & $\begin{array}{l}\text { Follow up } \\
\text { Control }\end{array}$ & Experiment \\
\hline Attachment & $.40(.143)$ & $.42(.120)$ & $.41(.157)$ & $.54(.102)$ & $.41(.151)$ & $.50(.095)$ \\
Well-being & $3.26(.552)$ & $2.95(.45)$ & $3.50(.565)$ & $4.12(.704)$ & $3.38(.458)$ & $4.31(.489)$ \\
\hline
\end{tabular}

In order to assess the significance of these differences, the Multivariate Analysis of Covariance (MANCOVA) from spss-19 was used (to control the pretest effect). The assumptions of normality of distribution of score in all measures (with Shapiro-Wilk test) and equality of variances (with Levene test) and covariance (with Box test) in the two groups were confirmed generally ( $p>0.01$ ). The results of analysis are presented in Table 3.

Table 3

Analysis of covariance of participants' scores

\begin{tabular}{lllllll}
\hline Index & & Total square & df & Mean square & F & Sig. \\
\hline \multirow{3}{*}{ Attachment } & Post-test & .250 & 1 & .250 & 37.424 & 0.000 \\
Well-being & Follow-up & .220 & 1 & .220 & 33.914 & 0.002 \\
& Post-test & 2.906 & 1 & 2.906 & 9.575 & 0.006 \\
& Follow-up & 1.229 & 1 & 1.229 & 6.637 & 0.018 \\
\hline
\end{tabular}


As Table 3 shows, there are significant differences in the post-test and follow-up test of attachment and well-being in the two groups.

\section{Discussion and conclusion}

The present study aimed to investigate the effectiveness of intervention of Circle of Security (COS) on shift of preschool children attachment and well-being. In particular, it was hypothesized that an insecure attachment style would be associated with negative parental rearing behaviors more than a secure attachment. Children with insecure attachment, which is believed to result from inconsistent and intrusive parenting, perceive less emotional support (Cassidy, 1995) in their relationship with their parent. A caregiver who interacts with their child in inconsistent and uncertain ways is not consistently meeting their child's emotional needs and may come across as less certain in the way they interact with their child. In the Circle of Security (COS), through watching films, seeing video clips of their children and themselves, reviewing interactions with their children, as the caregivers increase their capacity to observe and to reflect on the child's signals (Marvin et al., 2002). In this study, results showed significant difference between the mean score of attachment and well-being in the post-test and follow-up-test. These results represent significant changes in the preschool children attachment. This finding is consistent with Marvin et al., (2002); Hoffman et al., (2006); Brown and Whiteside (2008); and Panfil et al., (2012). In present study, we have also investigated the effectiveness of intervention of COS on shift of preschool children well-being. Several researchers showed that broad environmental circumstances could produce substantial and lasting differences in well-being. The child interacts first and foremost with the family and with a range of other people and systems. Young children are highly dependent on a nurturing and loving family. Children's living conditions, family situation, housing problems, and the quality of relationships within the family are crucial for children's well-being domains such as: physical, psychological, social, and cognitive (Bradshaw et al., 2011). White (2008) points out that child well-being change through their life-style. The present findings are in line with the results of White (2008) and indicated significant difference between the mean score of well-being in the post-test and follow-up-test in the two groups of control and experimental. Although, finding were not seen regarding associations between attachment and well-being in preschool children, but there are some evidence on associations between attachment and cognitive performance (West et al., 2012), conflicts (Panfile et al., 2012), self-regulation (Baker \& Hoerger, 2012), worry (Brown \& Whiteside, 2008), and socio-emotional adjustment (Baker \& Hoerger, 2012).

\section{References}

Ainsworth, M. D. S., Blehar, M. C., Waters, E., \& Wall, S. (1978). Patterns of attachment: A psychological study of the strange situation. Lawrence Erlbaum.

Baker, C. N., \& Hoerger, M. (2012). Parental child-rearing strategies influence self-regulation, socioemotional adjustment, and psychopathology in early adulthood: Evidence from a retrospective cohort study. Personality and individual differences, 52(7), 800-805.

Ben-Arieh, A. (2008). The child indicators movement: past, present, and future. Child Indicators Research, 1(1), 3-16.

Berlin, L. J., Zeanah, C. H., \& Lieberman, A. F. (2008), Prevention and intervention programs for supporting early attachment security. In J. Cassidy \& P. R. Shaver (Eds.), Handbook of attachment: Theory, research, and clinical applications (pp. 745-761), 2nd Ed. New York: Guilford Press.

Bowlby, J. (2008). Loss-Sadness and Depression: Attachment and Loss (Vol. 3). Random House.

Bowlby, J. (2005). The making and breaking of affectional bonds. Taylor \& Francis US.

Bradshaw, J., Keung, A., Rees, G., \& Goswami, H. (2011). Children's subjective well-being: International comparative perspectives. Children and Youth Services Review, 33(4), 548-556.

Bradshaw, J., Hoelscher, P., \& Richardson, D. (2007). An index of child wellbeing in the European. Union Social Indicators Research, 80, 133-177. 
Bronfenbrenner, U. (1986). Ecology of the family as a context for human development: Research perspectives. Developmental psychology, 22(6), 723.

Brown, A. M., \& Whiteside, S. P. (2008). Relations among perceived parental rearing behaviors, attachment style, and worry in anxious children. Anxiety Disorders, 22, 263-272.

Cassidy, J. (1995). Attachment and generalized anxiety disorder. In: Cicchetti D and Toth S. (Eds.), Emotion, cognition, and representation: Rochester Symposium on developmental Psychopathology VI. New York: University of Rochester Press.

Dehghani, A., Malekpoor, M., Abedi, A., \& Amiri, S.H. (2013). Development and Validation of Preschool Children Well-being Questionnaire (PCWQ), Journal of Research \& Health, [In press].

Erikson, E. H. (1968). Identity, psychosocial. International encyclopedia of the social sciences, 7, 61-65.

Hoffman, K. T., Marvin, R.S, Cooper G., \& Powell, B. (2006) Changing toddlers' and preschoolers' attachment classifications: The Circle of Security Intervention. Journal of Consulting and Clinical Psychology, 74, 1017-1026.

Lerner, R. M. \& Benson, P. L. (2004). Developmental assets and assets-building communities. Minneapolis: Search Institute.

Lippman, L. H. (2007). Indicators and indices of child well-being: a brief American history. Social Indicators Research, 83, 39-53.

Lippman, L. H., Moore, K. A., \& McIntosh, H. (2011). Positive indicators of child well-being: A conceptual framework, measures, and methodological issues. Applied Research in Quality of Life, 6(4), 425-449.

Malekpour, M. (2007). Effects of attachment on early and later development. The British Journal of Development Disabilities, 53(105), 81-95.

Marvin, R., Cooper, G., Hoffman, K., \& Powell, B. (2002). The circle of security project: Attachmentbased intervention with caregiver-pre-school child dyads. Attachment \& Human Development, 4(1), 107-124.

McCartney, K., Owen, M. T., Booth, C. L., Clarke-Stewart, A., \& Vandell, D. L. (2004). Testing a maternal attachment model of behavior problems in early childhood. Journal of Child Psychology and Psychiatry, 45(4), 765-778.

Panfile, T. M., Laible, D. J., \& Eye, J. L. (2012). Conflict frequency within mother-child dyads across contexts: Links with attachment security and gender. Early Childhood Research Quarterly, 27(1), 147155.

Rutter, M., Bishop, D., Pine, D., Scott, S., Stevenson, J., Tylor, E., \& Thaper, A. (2008). Rutter's child and adolescent psychiatry, ( $5^{\text {nd }}$ ed.) Blackwell publishing: Oxford, UK.

Scales, P. C., \& Benson, P. L. (2005). Presocial orientation and community service. In K. A. Moore \& L. Lippman (Eds.). What do children need to flourish? Conceptualizing and measuring indicators of positive development (pp. 339-356). New York: Springer.

Tabae Emami, Sh. (2012). Effectiveness of training Attachment of mothers in the 3-5 years children. $\mathrm{PhD}$ Thesis, University of Isfahan, Iran.

Tronick, E. Z. (1989). Emotions and emotional communication in infants. American Psychologist, 44, 112-119.

Waters, E. \& Deane, K. (1985). Defining and assessing individual differences in attachment relationships. Q-methodology and the organization of behavior in infancy and early childhood. Monographs of the Society for Research in Child Development, 50 (1), 41-65.

White, S. C. (2008, April). But what is well-being? A framework for analysis in social and development policy and practice. In Conference on Regeneration and Wellbeing: Research into Practice, University of Bradford (pp. 24-25).

Weinfield, N. S., Sroufe, L. A., Egeland, B. \& Carlson, E. (2008). Individual differences in infantcaregiver attachment: Conceptual and empirical aspects of security. In J. Cassidy \& P. R. Shaver (Eds.), Handbook of attachment: Theory, research, and clinical applications (2nd ed., vol, 7, pp, 78101). New York: Guilford Press.

West, K. K., Mathews, B. L., \& Kerns, K. K. (2012). Mother-child attachment and cognitive performance in middle childhood: An examination of mediating mechanisms. Early Childhood Research Quarterly, 42, 315-329. 